\title{
¿DESARROLLO MORAL O CONDUCTA MORAL?
}

Por

Alejandro David García V.

\section{RESUMEN}

El documento se desarrolla teniendo en cuenta las investigaciones morales en educación, en tal sentido se describen dos corrientes investigativas, una centrada en el juicio moral, por tanto son trabajos de carácter cognitivo, cuyos principales exponentes son Piaget y Kohlberg. La otra se centra en la conducta moral, estos estudios se originan en el comportamiento del sujeto. Algunos autores son Lickona, Bandura, Turiel, entre otros.

Por último se abordan los trabajos de Agusto Blasi, quien intenta conciliar las dos anteriores, estos trabajos son recientes y apenas se están posesionando en el discurso académico.

\section{PALABRAS CLAVES}

Carácter moral, Conducta moral, Desarrollo moral, Estadio o nivel, Juicio moral, Valor Moral.

*Filósofo de la Universidad Nacional de Colombia, Magister en Pedagogía y Desarrollo Humano, CINDE Universidad de Manizales, profesor asociado Departamento de psicopedagogía, Facultad de Educación, Universidad Surcolombiana. 
7 ablar de moralidad tiene su dilema, entre lo que piensa y hace, es decir, no existe una coherencia entre estos dos aspectos puesto que el ser humano como sujeto potencial siempre esta construyendo identidad, nunca es, sino que siempre está siendo. El sujeto conoce el mundo en la medida que lo aprehende y lo aprende, es decir, que lo percibe y lo interioriza; de modo que el sujeto conoce el mundo a través del aprendizaje, lo anterior significa dos cosas; una conocer el mundo es aprenderse, es decir, es interiorizar unos conocimientos que se convierten en conductas y que responden a las expectativas de mundo de la vida cotidiana del sujeto; el segundo aspecto del conocer, se concreta en que se aprende con los demás, en este aspecto, conocer es comunicar a otros un mundo de objetos expresados en un lenguaje.

Hablar de un conocimiento moral significa entonces partir de esas dos instancias que generan una inconsistencia subjetiva, ya que la persona se debate entre lo que piensa y lo que hace. Esto se ve reflejado en las teorías e investigaciones morales, pues existen actualmente dos vertientes que determinan y restringen la moralidad como una acción y como un desarrollo cognitivo. Este es un obstáculo que impide hablar de un planteamiento integrado de la educación moral en las ciencias sociales. Claro sintoma de ello es la diversidad de teorías que aluden a la moralidad, existe educación moral, educación en valores, educación social, educación del carácter, educación democrática.

¿Es posible hablar de una educación moral que implique tanto el hacer como el pensar en la acción del sujeto? ¿Cómo educar moralmente al niño teniendo en cuenta su desarrollo? Pues no es lo mismo educar a un niño de 6 años que a un niño de 12 años, mientras que con el primero habría que establecer unas pautas educativas que fortalezcan su conducta, con el segundo ya se podría ir creando unas expectativas que empiecen a cuestionar dichas conductas.

Piaget (1984) afirma que el desarrollo moral en el niño depende del tipo de relación social que éste establece con los demás y distingue dos tipos de relaciones: la moral heterónoma y la moral autónoma; la primera se fundamenta en la obediencia por miedo al castigo que pueda infringir quien ostente la autoridad, mientras que la segunda se basa en la igualdad y justicia que se da en las relaciones recíprocas de los niños. El gran aporte de Piaget está en la concepción del desarrollo moral como un cambio que va de la moral heterónoma a una moralidad autónoma, en tal sentido la autonomía se va logrando en la medida que el sujeto pueda reflexionar sobre sus propias acciones y para esto es indispensable el desarrollo de la inteligencia.

Para complementar Diaz y Medrano (1994) siguiendo a Piaget, afirman que la consistencia entre el juicio y la conducta moral solo es posible a partir de un nivel de autonomía. "Aunque el juicio moral cumpla un importante papel en la conducta, ésta depende, en gran parte, de otras características del propio sujeto (como su capacidad de autocontrol) y de la situación (como la atmósfera moral del grupo en el que tiene lugar la conducta)».

Esto significa que para hablar de educación moral en la infancia hay que aceptar el desarrollo de la moralidad desde la comprensión del pensar y hacer del «agente moral", para ello mostraré a continuación, a partir de Blasi una posible conciliación de estas dos líneas de trabajo; la conducta moral y el desarrollo del juicio moral; pues si nos atenemos a la conducta moral, formamos sujetos que actúan de acuerdo a las normas sociales, si educamos a partir de juicios morales, formamos sujetos que saben razonar bien pero 
que no son consecuentes con lo que hacen. Partir de una de las dos sería educar a una persona moral de un modo incompleto, pues si nos vamos por el juicio, fortalecemos los pensamientos; si tomamos la conducta, fortalecemos comportamientos. El ser humano es un ser que piensa y actúa, de ahi la necesidad de buscar la posible vinculación de las dos líneas de investigación moral.

\section{EL DESARROLLO MORAL}

Esta perspectiva, se fundamenta en los aportes hechos por Piaget y Kohlberg, y se sustenta en tres principios básicos y comunes:

\section{Considera la educación moral como}

un proceso de desarrollo que se basa en la estimulación del pensamiento sobre cuestiones morales, y cuya finalidad facilita la evolución de la persona a través de distintas etapas.

2. Formula fases o estadios en el desarrollo del juicio moral por los que va pasando el individuo.

3. Consiste en afirmar que los estadios o fases superiores son, desde el punto de vista moral, mejores y más deseables que los anteriores.

Con respecto al primero Piaget (1967) propone que la educación moral tiene como objetivo prioritario construir personalidades autónomas. Es por ello que la intervención educativa debe centrarse en el paso de la moral heterónoma a la moral autónoma. Para conseguirlo se deben proporcionar experiencias que favorezcan el abandono de la moral autoritaria y que, por el contrario, inviten a valorar y adoptar la moral del respeto y la autonomía.

Puig J (2002) citando a Piaget considera un primer nivel premoral, en el que no existe sentido de obligación respecto de las reglas. Un nivel heterónomo, que se caracteriza por el "realismo moral", es decir, por la influencia o presión que ejercen los adultos sobre el niño. En este nivel, las reglas son coercitivas e inviolables; son respetadas literal y unilateralmente por cuanto el niño aún no se diferencia del mundo social que le rodea, de manera que es una fase «egocéntrica». Por otra parte, la justicia se identifica con la sanción más severa. Esta fase estaría comprendida entre los cuatro y los ocho años.

Un nivel autónomo, en el que las reglas surgen de la cooperación entre iguales, el respeto y consentimiento mutuo. Las reglas se interiorizan y se generalizan hasta alcanzar la noción de justicia equitativa que implica el reparto racional en función de las situaciones.

En la propuesta de Piaget los niveles propiamente morales serian los dos últimos: el heterónomo y el autónomo. Entre ambos se da una relación de sucesión por la cual el niño pasa de la moral heterónoma a la autónoma.

Kohlberg, inicia sus estudios teniendo en cuenta la propuesta de Piaget (el paso de una moral heterónoma a una autónoma), pero realiza sus investigaciones redefiniendo los niveles y estadios establecidos por Piaget, instaurando seis estadios en el desarrollo del juicio' moral, que se agrupan en tres niveles distintos: preconvencional, convencional y postconvencional. 
El tercer aspecto común de los autores está en considerar los últimos niveles o estadios como más deseables moralmente que los primeros. Para Kohlberg los estadios superiores son más maduros que los inferiores, por cuanto suponen un crecimiento y un mayor equilibrio en la estructura formal del razonamiento de cada individuo. Los criterios empleados en los estadios superiores son más universales que los utilizados en los estadios inferiores.

Las conclusiones que Köhlberg (1989) deriva de sus trabajos son:

- La maduración moral depende de la interacción del desarrollo lógico y el entorno social.

- Cada etapa muestra un progreso con respecto a la anterior: desde el sometimiento a la autoridad externa de la primera hasta los principios universales de las dos últimas.

- Son los sujetos los que "construyen", en cada etapa más personal y autónomamente, el alcance de sus juicios morales.

- Si un sujeto madura físicamente sin sobrepasar las dos primeras etapas, permanece en ellas y se configura como un "tipo puro".

- Los sujetos que alcanzan las tres últimas no se configuran como «tipos puros» hasta alrededor de los veinticinco años.

\section{LA CONDUCTA MORAL}

Bajo este título incluimos las propuestas de educación moral que la entienden como adquisición de virtudes, formación del carácter o construcción de hábitos o conductas, los valores como creencias y los sentimientos morales. Dichas propuestas se están revitalizando impulsadas por factores sociales, culturales, filosóficos, y por el diálogo critico que mantienen con las posiciones cognitivorevolutivas del desarrollo moral.

Berkowitz (2002), afirma que la finalidad de la educación moral es la conducta, y para hablar de conducta moral es necesario tener en cuenta el carácter moral, y es con los trabajos de Lickona, (1993) y Ryan \& McLean, (1987) que la educación del carácter vuelve a tener vigencia. El argumento básico consiste en que la conducta moral se debe aprender, practicar y en última instancia interiorizar, como un carácter o virtud (en muchos casos basado en el modelo de virtud de Aristóteles). Es necesario demostrar y recompensar la conducta adecuada, de modo que se convierta en un hábito. Es el acto habitual el que deriva en el rasgo de carácter. Ello crea un círculo interesante con la conducta; ésta se modela y conforma correctamente por los métodos tradicionales de aprendizaje, lo cual conduce a tendencias interiorizadas que producen conductas correctas. De ahi la relación entre la conducta y el carácter.

Se puede afirmar entonces, que un rasgo distintivo del carácter moral es la convicción de que una persona es moral cuando mantiene una línea de conducta honrada; realiza actos virtuosos y los hace habitualmente. Para esta teoría es muy importante la formación de hábitos virtuosos y la configuración del carácter para construir una personalidad moral, es decir, los hábitos deben estar encaminados a la consecución del bien y la felicidad para reproducir las tradiciones de la colectividad. En esta postura hay una clara orientación finalista o teleológica, lo que supone la existencia de algo que permite establecer desde siempre aquello que es virtuoso o bueno para cada sujeto. En síntesis, una persona moral es aquella que se ha adherido a las tradiciones y valores sociales y los ha convertido en un conjunto de virtudes personales. 
También es importante tener en cuenta los trabajos de Bandura con respecto al moldeamiento de la conducta moral. Para este autor, el aprendizaje es una actividad donde el sujeto procesa información y los datos tanto conductuales como del entorno se transforman en representaciones simbólicas que sirven como lineamientos para la acción. El aprendizaje es un acto que consiste en aprender de las consecuencias de las propias acciones, o por la observación del desempeño de modelos. Al observar a los modelos, que pueden ser los padres, educadores, amigos, televisión, entre otros; el niño adquiere conocimientos que quizá no exhiba en el momento de aprenderlos pero que empleará cuando el entorno lo justifique. De modo que esta educación moral ofrece a los niños modelos adecuados por sus consecuencias positivas y las conductas deseables que aprende. El profesor es un modelo que sirve de aprendizaje al niño, como también, las actuaciones de sus compañeros.

Otros representantes de esta tendencia son los trabajos de: Peters, R.S.: «Desarrollo moral y educación moral» F.C.E. (1981). Nucci, L.P.: "Moral Development and character education", Berkeley, McCutrhan Publishing Corporation, (1989). Brezinka, W. (1987): «La habilidad (moral) como objetivo de la educación» y Medina, R. (1987): «Reflexiones sobre educación moral", ambos en Jordán, J.A. y Santolaria, F. (comps.): «La educación moral, hoy. Cuestiones y perspectivas». Barcelona, PPU. Desde una posición teórica distinta es de interés el trabajo de escámez, J.: «La formación de hábitos como teoría educativa». Murcia, Limites, 1984.
Con respecto a la relación existente entre conducta y valor, Delval y Enesco (1994: 60) dicen que "los valores determinan las reglas o normas de conducta, que indican cómo se debe uno comportar en distintas situaciones» en tal sentido la conducta moral se determina de acuerdo al sistema de valores y creencias de una sociedad.

Entrando a la problemática de los valores, ya que los investigadores tampoco se han puesto de acuerdo a este respecto, Rokeach, citado por Berkowitz (2002) define el valor como una p r e f e r e n c i a permanente para una conducta en concreto o para el alcance de un estado final de ser. Ello incluye tanto un claro c o m p o n e n t e cognitivo (una creencia), como un componente afectivo (la evaluación). Podemos apreciar que los valores y rasgos de carácter se e n c u e n tran estrechamente relacionados con características de definición que se ocultan.

Quizá la más clara distinción es que un rasgo de carácter es una tendencia a actuar de un modo determinado, y un valor es una tendencia a creer en la bondad o maldad de una acción o estado de situación. Este último posee un planteamiento más cognitivo, basado en el aspécto de creencia del valor.

Turiel (1984); da un avance al determinar un lugar más específico de los valores morales 
cuando distingue tres ámbitos de conocimiento social: el moral, constituido por su universalidad, inalterabilidad, prescriptividad y potencial intrínseco para herir; el socio-convencional, que se distingue por las costumbres y normas sociales que se reconocen especificas para cada contexto o grupo social determinado y que son modificables si la autoridad pertinente asi lo decide; y el personal, que pertenece al ámbito de los deseos y gustos propios. Los valores pueden pertenecer a cualquiera de estos tres tipos. La educación moral se debería preocupar básicamente de los valores morales, es decir, del conocimiento social como moral.

Por su parte Berkowitz, define los valores morales como: las creencias con carga afectiva, relativas a la corrección o equivocación de las cuestiones que son intrinseca y potencialmente perjudiciales, y que poseen un carácter universal e inalterable en su prescriptividad.

Esto nos lleva al afecto moral, pues resulta dificil imaginar a una persona moral desprovista de sentimientos.

Berkowitz dice que tradicionalmente existen dos grandes tendencias de emociones morales. La primera trabajada por Strawson P. (1995), recoge lo que podemos denominar las emociones de la autocritica; se trata de emociones de aversión que apuntan a algún tipo de autocensura o autovaloración negativa, como respuesta a un pensamiento o acción indeseable. Aqui se hace referencia a emociones tales como la culpabilidad, la vergüenza y el remordimiento. La segunda clase de emociones, la inicia Hume y Smith es de índole prosocial. Para Guisán (1986), estos sentimientos, juzgan las acciones porque se ajustan a la constitución de la naturaleza humana, es decir, la empatia como sentimiento original potencializa las relaciones humanas y la cooperación social, de modo que representan algún tipo de reacción afectiva ante la aflicción de los demás. Aquí se hace referencia a emociones tales como la empatia y la simpatía.

\section{LA IDENTIDAD MORAL}

Frisancho S (2001), afirma que es Agusto Blasi el primero en ofrecer una teoría que intenta llenar el vacío existente entre el razonamiento moral y la acción moral, teoria que conecta ambos aspectos con el concepto de self moral, y más particularmente, con el de identidad moral (Blasi, 1984).

Blasi, luego de revisar la relación entre el estadio de juicio moral en el sentido Kohlbergiano y el comportamiento, concluyó: que sibien existia relación entre conducta moral y estadio de desarrollo (pues las personas en estadios más avanzados manifiestan menor tendencia a mostrar conductas inapropiadas, en comparación co n personas de estadios inferiores), el poder de la asociación estaba lejos de ser perfecto, lo cual sugeria que otros factores más allá del juicio moral Kohlbergiano se vinculaban a la conducta moral.

La aproximación de Blasi se apoya en los trabajo de Erikson sobre la formación de la identidad, y está fuertemente influida por la teoría del desarrollo del yo de Loevinger. Blasi plantea que la teoría de Loevinger puede funcionar como un puente compatible hacia Kohlberg en la medida en que se trata de una teoria constructivista y transformacional. Basándose en Loevinger, plantea la posibilidad de que el enlace entre el 
juicio moral y la acción se encuentra en el grado en el cual la moralidad y las preocupaciones morales están integradas dentro del sentido de identidad (sense of self) de la persona. La idea básica es que a partir de la identidad moral se deriva la necesidad psicológica de hacer que nuestras acciones sean consistentes con los propios ideales. En palabras de Blasi (1993), "la consistencia con el propio self es el resorte motivacional de la acción moral».

En este sentido, los motivos para la acción moral no son resultado directo de "conocer" lo bueno o lo justo, sino que surgen de un deseo

de actuar de forma tal que podamos mantener la consistencia de nuestro sentido de identidad como seres morales, para asi convertirnos o seguir siendo 2 cierto tipo de ser ity humano.

Lo interesante 1 del concepto de identidad moral o moral self es que éste no intenta reemplazar las ideas morales con conceptos no cognitivos (como el concepto tradicional de carácter, basado en una concepción de virtudes como rasgos de personalidad), sino que, como afirma Blasi (1993), "ve a la identidad personal operando conjuntamente con la razón y la verdad en proveer motivos para la acción».

La investigación acerca de la identidad moral recién ha empezado, pero los trabajos de Blasi y sus colaboradores demuestran que para algunas personas, la moral penetra la esencia misma de lo que son como seres humanos, mientras que para otras el sentido de identidad se construye de manera distinta, lo que significaria que los aspectos morales de la identidad se experimentan subjetivamente de diferentes modos. Esta línea de investigación resulta promisoria, aunque aun no existen datos concluyentes sobre cómo la identidad moral se vincula al comportamiento.

Una vez establecidas las dos tendencias y su posible conciliación, veamos como se desarrollan estas en la educación.

\section{LA EDUCACIÓN MORAL A TRAVÉS DE JUICIOS MORALES}

Actualmente se conocen dos maneras de educar para un razonamiento moral: la discusión de dilemas morales entre iguales y la Comunidad Justa.

La educación a partir de dilemas morales se inicia con Kohlberg, estos se caracterizan por la oposición de valores diferentes, propiciando la discusión de entre iguales. Los dilemas morales se seleccionan de forma apropiada entre las antologias, los acontecimientos actuales, la historia, la literatura, el curriculum, o los elabora el mismo profesor. El grupoclase (u otro grupo de estudiantes) empieza entonces un proceso de discusión critica pero respetuosa a partir del dilema, con el explícito objetivo de intentar determinar cuál seria la mejor solución. Tal y como se demostró en Berkowitz \& Gibbs (1983), la discusión entre iguales es la que promueve mayor desarrollo. El papel del educador es el de facilitar y activar consideraciones acerca del razonamiento.

La Comunidad Justa propuesta por kohlberg, ha sido puesto en práctica con éxito en variedad de contextos, incluyendo escuelas, centros residenciales de tratamiento (Blakeney \& Blakeney, 1990), prisiones (Hickey \& Scharf, 1980) y lugares de trabajo (Higgins \& Gordon, 1985). El punto central del enfoque basado en la Comunidad Justa es el autogobierno democrático encaminado a promocionar la justicia y el sentido de comunidad. Las decisiones se toman mediante procedimientos directos, democráticos y de tipo parlamentario, pero con 
un explícito interés por maximizar la justicia en las decisiones y por intentar crear y afirmar un sentido de identidad comunitaria en el grupo.

\section{LA EDUCACIÓN A PARTIR DE'LA CONDUCTA MORAL}

Bandura considera el desarrollo moral como un proceso de interiorización de normas y prohibiciones socialmente sancionadas. Básicamente, esta posición mantiene que el niño va aprendiendo y asumiendo conductas en función de que estas sean castigadas o recompensadas. El niño aprenderá que ciertas cosas están mal porque serán castigadas de algún modo y aprenderá que otras están bien o son correctas porque cuando las haga será recompensado por ello.

El niño aprende conductas directas a través de la imposición de normas por parte de la autoridad, pero el niño también aprende indirectamente mediante la observación y la representación simbólica de otras personas y situaciones

Berkowitz (2002) afirma que: «Para educar moralmente a los niños pre-escolares es necesario ocuparse de: (1) la calidad de las relaciones del niño, en especial con aquellas otras personas significativas en su vida (Magid \& McKelvey, 1987); (2) la enseñanza de modelos de conducta, incluyendo la disciplina y la orientación; (3) la conducta presentada al niño como modelo; y (4) los procedimientos de toma de decisiones y los modelos de comunicación de la familia (Berkowitz, 1992). Ciertamente estos son ámbitos que se solapan. Sabemos que los niños desarrollan personalidades más sanas con los demás si quienes se ocupan de ellos son cariñosos y coherentes, si responden, si son idóneos y sensibles a las indicaciones del niño. Sabemos que la enseñanza de la conducta resulta muy efectiva cuando se basa en la recompensa de la conducta deseada y no en el castigo por 1 conducta indeseada».

Berkowitz deja claro que las familias que usan el poder autoritariamente y opresor, a través de decisiones estrictas, conductas rígidas, unidireccionales y jerárquicas, producen niño: menos sanos y menos morales. En tal sentido debe buscarse la manera como las familias. través de la comunicación abierta y en una toma de decisiones colectiva y democrática asuma un respeto por los niños y por sus aportaciones a los asuntos familiares.

La escuela por tanto se encarga de la formación moral del niño de dos maneras: una como facilitadora y otra como subsanadora. La educación moral es facilitadora cuando la escuela complementa los efectos positivos de la familia sobre la formación moral. La escuela es subsanadora cuando reemplaza y corrige las influencias negativas de la familia en el niño/a.

Siguiendo con Berkowitz, se puede afirmar que el carácter influye en el desarrollo de personalidad, por tanto, la educación del cà moral debe ir más allá de la conducta deseacáa, puede y debería incluir un planteamiento sobre la inculcación de creencias. De ahí que, su objetivo principal es el desarrollo de hábitos morales, de tendencias de conducta, que es de esperar germinen de por sí rasgos de carácter o virtudes. Teniendo en cuenta lo anterior, vemos como los programas escolares se deben centrar en la implementación de buenos hábitos de manera controlada, de tal modo que cuando sus jóvenes estudiantes maduren, tales hábitos queden profundamente arraigados y generalizados en la sociedad.

Por otra parte, la educación del carácter puede ejercer una influencia en el modelado de actitudes y de valores como creencias. Ello significa que la enseñanza de valores debería ser una parte de la educación del carácter; de hecho debe serlo, ya que la reflexión sobre los valores 
propios es un aspecto crítico de la transformación de hábitos en carácter.

Debemos recordar también que los valores proceden de una serie de fuentes, pueden derivar de la enseñanza explícita verbal de los mismos; se pueden aprender de modelos de conducta de los demás; se pueden aprender de individuos o de instituciones; se pueden aprender de la autoridad del adulto y de los pares. Por ello, las escuelas deben ocuparse de muchos mecanismos y fuentes de educación en valores. Allí reside, ciertamente, la capacidad de descubrir «el currículum oculto» de una escuela.

La durcación moral a través de valores en la escuela, también se rige por dos supuestos: Uno esta en la búsqueda de un conjunto universal de valores (Josephson, 1993); el otro se concreta n la generación local de un conjunto de valores civicos, democráticos y humanos, que dependen del lugar (nación, región, hasta la comunidad local, el distrito académico, la escuela o incluso la clase) y de su historia.

Por último, la Educación del afecto moral es mucho más compleja, hecho que se constata en las siguientes razones: La primera y principal está en que la mayoria de los informes psicológicos acerca de las emociones morales sugiere que éstas se desarrollan principalmente con el ingreso a la escolarización formal (p.e. Dunn, 1987; Emde, Johnson \& Easterbrooks, 1987; I Ioffman, 1987; Kagan, 1981). La segunda razón es que se ha investigado poco sobre la educación de las emociones morales en la escuela. La tercera es, que la mayoría de los estudios sobre el afecto moral se ha centrado por los remedios y por la falta de una vida emocional tipica (p.e., Megid \& McKelvey, 1987).

De todas maneras estos motivos no son obstáculo para hacer un acercamiento con respecto a la educación de las emociones morales. Berkowitz comienza por la experiencia pre- escolar, los estudios de las emociones morales que provienen de la empatia, asumen que sus orígenes se remontan a un vinculo temprano que se establece entre el niño y quien lo cuida (Kaye, 1982). Por consiguiente, el niño ya iría a la escuela con capacidades empáticas.

Pero recordemos que existen otras emociones morales en el niño/a cuando va al colegio, emociones como: culpabilidad, vergüenza, resentimientos, orgullo, entre otras (Emde et al., 1987; Gilligan, 1976), por el acoso y maltrato de los pares. Estas situaciones hacen que el niño crea que sus sentimientos empáticos son un signo de debilidad o son de algún modo equivocados. El comentarlos y normalizarlos le puede servir para reducir sus dudas sobre el valor de sus propios sentimientos.

Asi pues, lo único que le queda a la escuela por hacer es, orientar al niño hacía el bien y detestar el mal, pero desafortunamente, no es claro cómo se debe hacer. Bennett (1991), por ejemplo, es partidario del «alfabetismo moral" en la infancia como un medio de enseñarle qué es el bien. Desde esta perspectiva, la enseñanza a los niños/as en las escuelas debería versar sobre virtudes morales, sobre héroes morales, sobre grandes hazañas morales, y poner a los niños/as en contacto con la gran literatura moral.

Existe también la necesidad de ayudar a los niños/as a identificar sus emociones morales, frecuentemente no poseen etiquetas verbales para lo que sienten o no saben qué etiquetas aplicar en un caso concreto. La comunicación de los sentimientos morales y su nominalización no sólo reduce la confusión de un niño sobre sus sentimientos, sino puede servir para legitimarlos.

En sintesis, a pesar de las dificultades que presentan las emociones morales, las escuelas deben procurar enseñar acerca de las emociones 
morales, para modelarlas, y así ayudar a los niños a expresar, nominalizar y dirigir sus emociones morales.

\section{CONCLUSIONES}

1. Con respecto al juicio moral, cabe señalar las críticas dirigidas al excesivo énfasis dado a los factores cognitivos en detrimento de los motivacionales conductuales; o los reparos lanzados contra la omisión de los efectos positivos que puede producir la enseñanza explícita y directa de la moral en el criterio ético de los alumnos; o bien la escasa atención que se presta a las diferencias individuales en el ritmo del desarrollo moral. Asimismo, son fuentes de critica el limitado reconocimiento del papel educativo de las formas sociales y de los productos culturales que la humanidad ha ido acumulando. Por último se le cuestiona el hecho de que el sujeto enjuicia moralmente desde situaciones hipotéticas, muy alejadas de las realidades contextuales sobre las que pretende cnseñar.

Por su parte las falencias que plantean los estudios sobre la conducta moral, esta en que el sujeto moral no cuestiona, ni se pregunta por el origen de la norma, hay una aceptación de la autoridad incuestionadamente.

Otro punto débil de esta propuesta es dar por establecidos y claros los contenidos de tales hábitos virtuosos. Dichos contenidos son dificiles de fijar, ya que nos encontramos en sociedades plurales, en las que conviven proyectos de vida distintos. En esos casos el contenido de los hábitos no puede estar prefijado, sino que debe construirse en relación a las propias expectativas personales, a las situaciones de vida con las que cada cual se encuentra, $y$ a la gama de problemas que cada sujeto debe solucionar.

La convicción de que la civilización ha acumulado un amplio conjunto de formas que deben conservarse y transmitirse vigorosamente a las jóvenes generaciones, es lo que ha 4 dado una gran trascendencia al papel de la escuela y de los educadores.

2. La educación moral por tanto se debate entre desarrollar razonamientos morales a través de dilemas entre iguales o de la organización del gobierno escolar en comunidades justas, fundándose en unos valores éticos de carácter universal como lo proponia kant. Es un proyecto que se puede vincular convalidando los derechos humanos y universales, en la búsqueda de una sociedad más justa y equitativa en la medida que los actores aprendan a desenvolverse y solucionar problemas a través del diálogo.

La educación moral se puede dar también a través de estrategias conductuales que permitan al niño adquirir hábitos que generen comportamientos virtuosos de respeto, honradez y bondad. Conductas que se modelan a partir de valores idóneos para una sociedad en particular, generalmente son valores humanos que se consolidan a través de las acciones particulares de los sujetos. Por tanto la escuela debe determinar cuales son los hábitos que desea 
implementar en los niños y adultos que la conforman para establecer pautas de convivencia que sus actores puedan reproducir culturalmente en la sociedad.

La educación moral como formación de hábitos virtuosos trata de propiciar la adquisición de conductas que puedan ser consideradas como virtuosas, es decir, que expresen valores socialmente arraigados y propios de una comunidad humana, o bien que expresen los valores que conducen hacia la felicidad que puede esperar cada ser humano. Es en esta dirección que la conducta moral hace sus mejores aportes, ver lo moral como algo fundamentalmente relacionado con hábitos virtuosos, con formas de ser y de comportarse.
Queda de todas maneras la inquietud sobre que tipo de personas se están formando moralmente en un mundo cambiante y que deja cada vez más explicito las desigualdades sociales. Sabemos que con solo intenciones morales no se pueden alcanzar cambios, por tanto es necesario que se fomente una formación moral que fortalezca la identidad de los sujetos, junto con unos procesos de socialización que consoliden su pertenencia a una comunidad.

3. El ser humano, como sujeto indeterminado es una unidad en la multiplicidad, por tanto debe buscar las maneras como pueda conciliar sus propias inconsistencias con sus virtudes. Implica la formación de un humano que acepte la incertidumbre como parte de su existencia, y que busque a través de dicha inconsistencia la complementariedad entre lo que hace y lo que piensa.

\section{BIBLIOGRAFÍA}

BERKOWITZ, M. (2002) Revista Iberoamericana de Educación No. 8.

DELVAL, J. ENESCO, I. (1994) moral, desarrollo y Educación. Anaya. Madrid.

FRISANCHO S. (2001) Ponencia presentada en el marco de la Cátedra Andina de Educación en Valores. Lima, Noviembre.

GUISAN, E. (1986) razón y pasión en ética. Antrophos. Barcelona.

KOHLBERG, L. (1989) estadios morales y moralización, en «El mundo social en la mente infantil». Alianza. Madrid.
PIAGET, J. (1967): «Los procedimientos de la educación moral" en Piaget, J.; Petersen, P.; Wodehouse, H. y Santullano, 1. en «La nueva educación moral», Buenos Aires, Losada.

PIAGET, J. (1984) El criterio moral en el niño. Barcelona, Martinez-Roca.

PUIG, J. (2002) La construcción dialógica de la personalidad moral, En: www.revista Iberoamerica de educaciòn.

STRAWSON, P. (1995) Libertad y Resentimiento. Paidos. Barcelona.

TURIEL, E. (1984) El desarrollo del conocimiento social. Moralidad y convención. Debate. Madrid. 


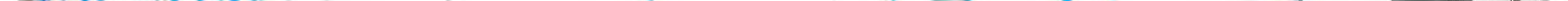

